\title{
Posterior fusion and implantation of the SOCON-SRI system in the treatment of adult spondylolisthesis
}

\section{Giovanni La Rosa, M.D., Antonino Germanò, M.D., Alfredo Conti, M.D., Fabio Cacciola, M.D., Gerardo Caruso, M.D., and Francesco Tomasello, M.D.}

Neurosurgical Clinic, University of Messina School of Medicine, Messina, Italy

Surgery for adult patients with lumbar and lumbosacral spondylolisthesis is reserved for those with intractable radiculopathy, claudication, or symptomatic spinal instability. Internal fixation, in which posterior fusion, transpedicular screw fixation, and implantation of titanium devices are performed, has been advocated to improve fusion rates and clinical results. Fourteen consecutive patients with Grade II to III lumbar and lumbosacral spondylolisthesis who underwent posterior decompression, reduction, autologous posterior facet joint arthrodesis, and SOCON-SRI implantation are retrospectively reviewed.

All patients underwent complete preoperative clinical and neuroradiological evaluation. Treatment consisted of posterior decompressive surgery and implantation of the SOCON-SRI system (transpedicular screws, prebent longitudinal rods, and one locking-screw clamps). Distraction of the interbody space and rotation were performed to achieve an optimum spinal realignment. The facet joints were fused by using autologous bone graft. The authors obtained detailed clinical, functional, economic, and neuroradiological follow-up data for up to 14 months (range 8--18 months).

The efficacy of the treatment was evaluated by comparing pre- and postoperative data. Pain was decreased in all cases, neurological dysfunction ameliorated in 50\%, and functional and economic status was improved in $78 \%$ and $100 \%$, respectively. No cases of fusion failure or instrumentation-related complications occurred. The authors describe their results of treating patients with spondylolisthesis in the light of the rationale for surgery and the more recent pertinent literature.

\section{Key Words * pedicle screw * SOCON-SRI system * spinal fusion * spinal instrumentation *} spondylolisthesis

Spondylolisthesis is the anterior subluxation of one vertebral body onto another, usually L-5 onto S-1, and it occasionally affects the upper lumbar spinal segments. Spondylolisthesis can be caused by ligamentous laxity and trauma, and it occurs in people of all ages in up to $5 \%$ of the general population. [8-10] Operative management for adults with nontraumatic spondylolisthesis is generally reserved for treating progressive neurological deficits, intractable low-back pain associated with radiculopathy, claudication, or symptomatic spinal instability with the goal of achieving spinal 
stabilization, fusion, and resolution of symptoms.[2,20,25] When surgery is performed, fusion is mandatory for isthmic, degenerative, and iatrogenic spondylolisthesis, especially when wide decompressive surgery has been performed, to prevent eventual progression of disc slippage.[2,7,25]

The numerous devices in the treatment of spondylolisthesis described in the literature include systems of screws and rods, sublaminar wires, hooks, and cables. However, fusion rates in patients who have undergone surgery for spondylolisthesis may sometimes be suboptimum. In addition, because some devices are not yet approved by the United States Food and Drug Administration for general use in the lumbar spine, their use may represent a possible source of medicolegal concern for spinal surgeons.

Recently, the use of modern dynamic titanium systems, which are characterized by transpedicular screws with constrained screw/rod connections, seems to be more effective than previously used systems.[3,11,13,19,27] These titanium systems allow for vertebral spatial mobilization, precise reductive maneuvers, and improved spinal fusion and, therefore, result in better clinical outcome for spondylolisthesis. The SOCON-SRI system (Aesculap AG CO., KG, Tuttlingen, Germany) is a titanium internal fixation device consisting of self-locking clamps with transpedicular bone screws that are connected with straight reduction rods, which allows compression and distraction of the lower thoracic and lumbar spine in stabilization and fusion procedures.[19,23,26]

We describe our experience, using carefully defined indications for surgery in the light of the more recent literature, in the treatment of 14 consecutive patients with high-grade symptomatic lumbar and lumbosacral spondylolisthesis who underwent posterior decompressive surgery, facet joint fusion with autologous bone graft, and implantation of SOCON-SRI system.

\section{CLINICAL MATERIAL AND METHODS}

\section{Demographic, Clinical, and Selection Data}

Between June 1998 and June 1999 at the Neurosurgical Clinic, University of Messina, we treated 14 adult patients from the general population admitted with the diagnosis of lumbar and lumbosacral spondylolisthesis; all 14 patients underwent fusion combined with implantation of the SOCON-SRI system. The mean age of the patients was 56.4 years (range 49--67 years); there were eight women and six men. Spondylolisthesis was classified as isthmic in five and degenerative in nine. Preoperatively no patient was invloved in any claims for workers' compensation or litigation following accidents, and cases of spondylolisthesis were related to previous lumbar surgery.

Symptoms consisted of back, buttock, and posterior thigh claudication pain or lumbosacral radiculopathy in all patients. Examination revealed neurological deficits that correlated with radiographically demonstrated pathological processes in 11 patients (79\%). Deficits consisted of dermatomal sensory loss in eight $(57 \%)$, diminished or absent reflexes in eight (57\%), a positive Lasegùe's sign in six (43\%), weakness and motor disturbances in five (36\%), and urinary incontinence in three $(21 \%)$. Four patients were cigarette smokers (Table 1). 
SUMMARY OF PRE AND POSTOPERATIYE DEMOGRAPHC, CL NICAL, ECONOMIC, FUNCTIONAL, AND RADIOLOGICAL DATA IN 14 SURGKALLV TREATED PATIENTS WITH HIGH-GRADE SPONDVLOLISTHESE*

\begin{tabular}{|c|c|c|c|c|c|c|c|c|c|}
\hline \multirow[b]{2}{*}{$\begin{array}{l}\text { Case } \\
\text { No. }\end{array}$} & \multirow[b]{2}{*}{$\begin{array}{l}\text { Age } \\
(y-s), \\
\text { Sex }\end{array}$} & \multirow[b]{2}{*}{ Level } & \multirow[b]{2}{*}{ Cause } & \multicolumn{3}{|c|}{ Preop Data } & \multicolumn{2}{|c|}{ Postop Data } & \multirow[b]{2}{*}{$\begin{array}{l}\text { Ciga- } \\
\text { rette } \\
\text { Smok }\end{array}$} \\
\hline & & & & Neurdogical Status & $\begin{array}{l}\text { Economic \& } \\
\text { Functional } \\
\text { Grades }\end{array}$ & $\begin{array}{l}\text { Slip- } \\
\text { page }\end{array}$ & $\begin{array}{l}\text { Economic \& } \\
\text { Functional } \\
\text { Grades }\end{array}$ & $\begin{array}{l}\text { Slip- } \\
\text { page }\end{array}$ & \\
\hline 1 & $49, \mathrm{M}$ & L5-S1 & I & $\begin{array}{l}\text { LBP, Lasèque's sign, } \\
\text { claudication, hypo- } \\
\text { reflexia, sensory } \\
\text { disturbances }\end{array}$ & $E 2, F 2$ & $50 \%$ & E4, F4 & $20 \%$ & yes \\
\hline$\frac{2}{3}$ & $\begin{array}{l}53, \mathrm{M} \\
63, \mathrm{~F}\end{array}$ & $\begin{array}{l}\llcorner 4-5 \\
\mathrm{L}-4\end{array}$ & $\begin{array}{l}\text { I } \\
\mathrm{D}\end{array}$ & $\begin{array}{l}\text { LBP, Lasegue's sign } \\
\text { LBP, hyporeflexia, } \\
\text { sersory disturbances }\end{array}$ & $\begin{array}{l}\mathrm{E} 4, \mathrm{F3} \\
\mathrm{E} 3, \mathrm{~F} 4\end{array}$ & $\begin{array}{l}30 \% \\
50 \%\end{array}$ & $\begin{array}{l}\mathrm{E} 5, \mathrm{F5} \\
\mathrm{E} 4, \mathrm{~F} 4\end{array}$ & $\begin{array}{l}15 \% \\
15 \%\end{array}$ & $\begin{array}{l}\text { no } \\
\text { no }\end{array}$ \\
\hline 4 & $55, \mathrm{M}$ & L4-5 & $\mathrm{D}$ & LBP, paraparesis, & $E 2, F 3$ & $55 \%$ & $\mathrm{E} 3, \mathrm{~F} 4$ & $20 \%$ & no \\
\hline 5 & $52, \mathrm{~F}$ & L5-S1 & $\mathrm{D}$ & LBP, paraparesis, & $E 2, F 2$ & $55 \%$ & $E 3, F 3$ & $20 \%$ & yes \\
\hline 6 & $67, \mathrm{~F}$ & $\stackrel{\mathrm{L} 3-4}{\mathrm{~L} 4-5}$ & I & $\begin{array}{l}\text { LBP, Lasegue's sign, } \\
\text { motor \& sersory } \\
\text { deficits, hyporeflexia, } \\
\text { urinary incontinence }\end{array}$ & $\mathrm{E} 1, \mathrm{~F} 1$ & $65 \%$ & $E 2, F 2$ & $25 \%$ & no \\
\hline $\begin{array}{l}7 \\
8\end{array}$ & $\begin{array}{l}54, \mathrm{M} \\
50, \mathrm{~F}\end{array}$ & $\begin{array}{l}\text { L5-S1 } \\
\text { L5-S1 }\end{array}$ & $\begin{array}{l}\mathrm{D} \\
\mathrm{D}\end{array}$ & $\begin{array}{l}\text { LBP } \\
\text { LBP, Lasègue's sign, } \\
\text { hyporeflexia, sensory }\end{array}$ & $\begin{array}{l}\mathrm{E} 4, \mathrm{F3} \\
\mathrm{E} 3, \mathrm{F3}\end{array}$ & $\begin{array}{l}35 \% \\
45 \%\end{array}$ & $\begin{array}{l}\text { E5, F5 } \\
\text { E4, F3 }\end{array}$ & $\begin{array}{l}15 \% \\
20 \%\end{array}$ & $\begin{array}{l}\text { no } \\
\text { no }\end{array}$ \\
\hline $\begin{array}{r}9 \\
10 \\
11\end{array}$ & $\begin{array}{l}54, \mathrm{~F} \\
51, \mathrm{M} \\
64, \mathrm{~F}\end{array}$ & $\begin{array}{l}\text { L4-5 } \\
\text { L5-S1 } \\
\text { L4-5 }\end{array}$ & $\begin{array}{l}\mathrm{I} \\
\mathrm{D} \\
\mathrm{D}\end{array}$ & $\begin{array}{l}\text { LBP } \\
\text { LBP, Lasègue's sign } \\
\text { LBP, paraparesis, } \\
\text { urinary incontinence }\end{array}$ & $\begin{array}{l}\mathrm{E} 3, \mathrm{~F} 2 \\
\mathrm{E} 3, \mathrm{~F} 2 \\
\mathrm{E} 1, \mathrm{~F} 1\end{array}$ & $\begin{array}{l}40 \% \\
45 \% \\
60 \%\end{array}$ & $\begin{array}{l}\mathrm{E} 5, \mathrm{~F} 4 \\
\mathrm{E} 4, \mathrm{~F} 4 \\
\mathrm{E} 2, \mathrm{~F} 3\end{array}$ & $\begin{array}{l}15 \% \\
15 \% \\
25 \%\end{array}$ & $\begin{array}{l}\text { yes } \\
\text { yes } \\
\text { no }\end{array}$ \\
\hline $\begin{array}{l}12 \\
13 \\
14\end{array}$ & $\begin{array}{l}61, \mathrm{M} \\
60, \mathrm{~F} \\
57, \mathrm{~F}\end{array}$ & $\begin{array}{l}\text { L5-S1 } \\
\text { L5-S1 } \\
\text { L5-S1 }\end{array}$ & $\begin{array}{l}\mathrm{D} \\
1 \\
\mathrm{D}\end{array}$ & $\begin{array}{l}\text { LBP, claudication } \\
\text { LBP' } \\
\text { LBP, Lasègue's sign, } \\
\text { paraparesis, rypo- } \\
\text { reflexia, urinary } \\
\text { incontinence }\end{array}$ & $\begin{array}{l}\mathrm{E} 2, \mathrm{~F} 2 \\
\mathrm{E} 3, \mathrm{~F} 2 \\
\mathrm{E} 1, \mathrm{~F} 1\end{array}$ & $\begin{array}{l}55 \% \\
45 \% \\
60 \%\end{array}$ & $\begin{array}{l}\mathrm{E3}, \mathrm{F3} \\
\mathrm{E} 5, \mathrm{F4} \\
\mathrm{E} 2, \mathrm{~F} 3\end{array}$ & $\begin{array}{l}20 \% \\
20 \% \\
20 \%\end{array}$ & $\begin{array}{l}\text { no } \\
\text { no } \\
\text { no }\end{array}$ \\
\hline
\end{tabular}

Preoperative and postoperative economic (activity) and functional (pain) statuses were assessed and classified according to the grading system proposed by Prolo, et al.,[22] (Table 1).

In those patients selected for surgery conservative medical treatment, including bedrest, antiinflammatory medication, physiotherapy, and external bracing, had failed to resolve symptoms.

\section{Neuroradiological Studies}

The preoperative radiographic evaluation consisted of standard anteroposterior, lateral, oblique, and flexion--extension views (Fig. 1 left). The percentage of slippage was measured, according to the Meyerding's classification for spondylolisthesis.[16] Slippage was classified as Grade II (eight patients) and Grade III (six patients) lumbar or lumbosacral spondylolisthesis. In all patients there was radiographic evidence of spondylolisthesis or translational motion of $3 \mathrm{~mm}$ or greater. The study was completed by obtaining computerized tomography studies with bone views and magnetic resonance (MR) imaging studies to detail the extent of neural compression (Fig. 1 right). 


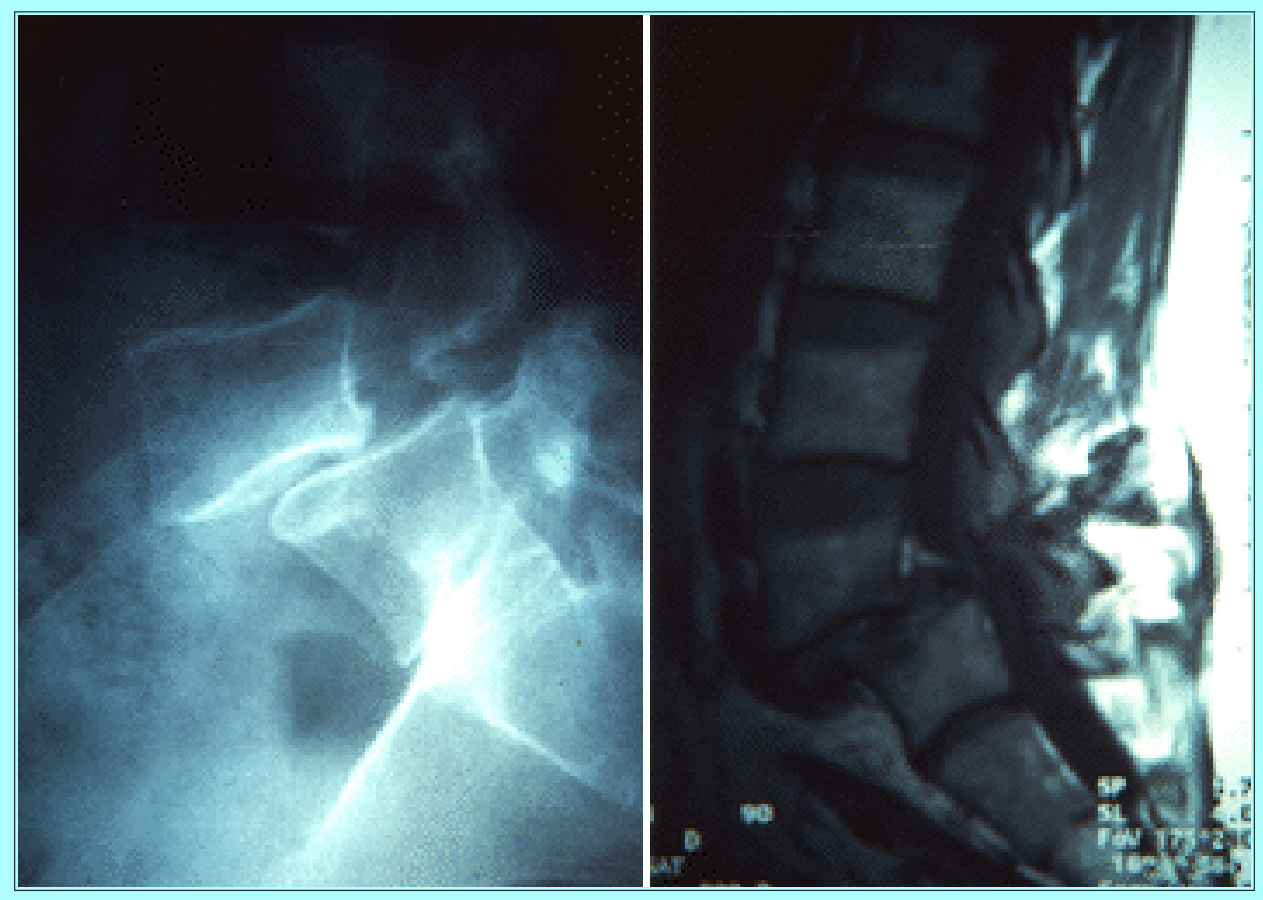

Fig. 1. Left: Preoperative lateral x-ray film demonstrating an isthmic L4--5 spondylolisthesis with slippage measured at $54 \%$. Right: Preoperative sagittal $\mathrm{T}_{1}$-weighted $\mathrm{MR}$ image confirming the L4--5 spondylolisthesis associated with disc herniation at the same level, which exerts significant compression on the neural structures.

\section{Operative Technique}

All patients underwent internal fusion combined with implantation of the SOCON-SRI system. The decompressive procedure consisted of spinous process removal, bilateral laminectomy, partial bilateral facetectomy, and foraminotomy. The disc spaces were carefully checked for herniated disc material or prominent bulges, and when necessary, the discs were removed. Following graft harvest, decortication with high-speed drill, and packing of the facet joint, pedicle screws were sized to occupy $70 \%$ of pedicle diameter. The pedicles typically accepted 5 to $6 \mathrm{~mm}$ screws, which were inserted and advanced, using fluoroscopic guidance, in rostrocaudal orientation to the anterior cortex of the vertebral body, maintaining a trajectory that is parallel to the end plate. To determine both the length of the rod and its contour, should it need to the bent, a malleable tube is used as a template for the rod. The rods were bent to match the template and attached to the pedicle screws with the use of one-locking clamps. The transpedicular bone screws have an attachment for the adaptation of reduction levers. Following distraction by means of the longitudinal threaded spindle, spondylolisthesis reduction was performed by operating either the removable lever or the adjusting screw. When reduction was completed, the system was securely fixed using a dedicated torque wrench. At this point, a facet joint fusion procedure was performed. The joint capsules were entered using a sharp rongeur, the cartilage was removed, and the cancellous bony surfaces were exposed. The joints were then packed tightly with autologous cancellous bone graft obtained from the spinous processes.

\section{Postoperative Course and Follow Up}

All patients were mobilized within 3 days after surgery, and a semirigid lumbosacral brace-dressing was prescribed for the following 5 months. Rehabilitative therapy was initiated within the 1 st week. All patients underwent serial clinical follow-up evaluations, for periods ranging between 2 and 18 months. Radiographs were obtained postoperatively and at regular intervals to evaluate the reduction of 
spondylolisthesis and to identify the correct placement and stability of the implant system (Fig. 2).

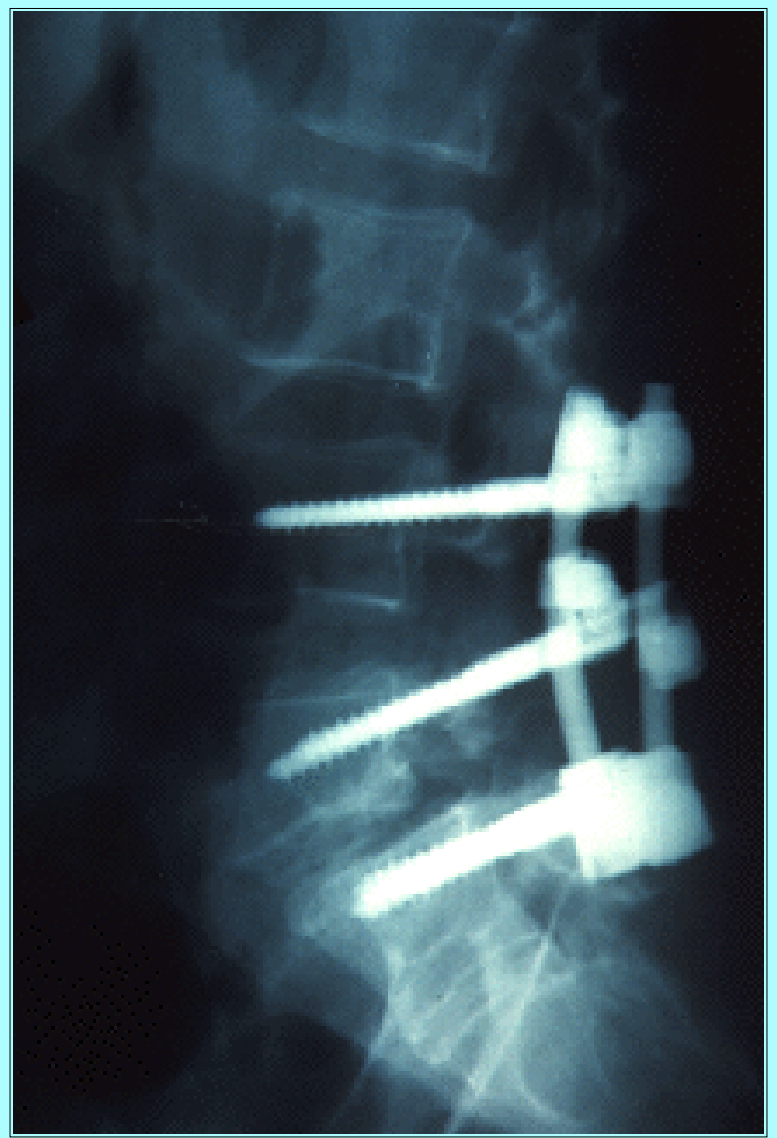

Fig. 2. Postoperative lateral x-ray film revealing the reduction of spondylolisthesis, as well as the correct positioning of the SOCON-SRI system. The slippage has been reduced to $20 \%$.

The mean radiographic follow-up period was 14 months (range 8--18 months), and successful fusion was defined as the presence of bilateral continuous trabecular bone between fixed segments. Postoperative computerized tomography scanning with bone window views and magnetic resonance imaging studies to evaluate the neural decompression were obtained in all patients (Fig. 3). 


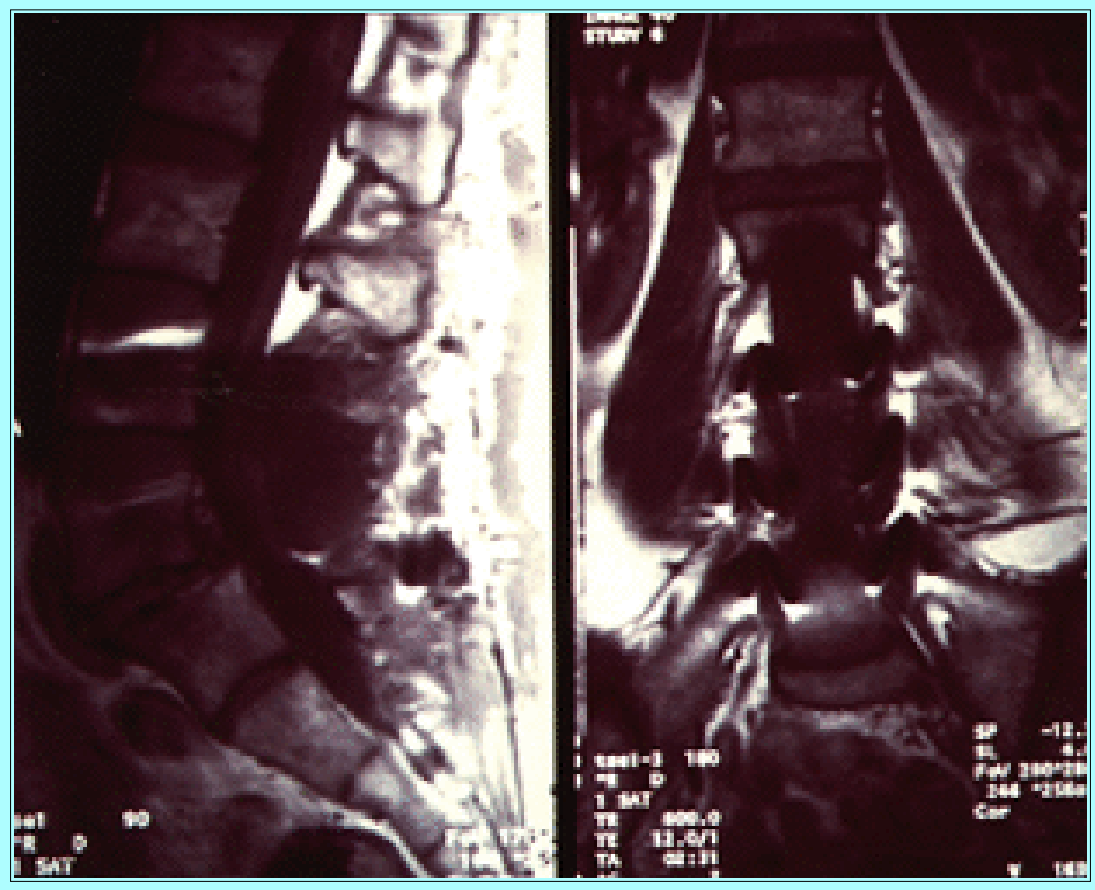

Fig. 3. Postoperative $T_{1}$-weighted $M R$ images (sagittal [left] and coronal view [right]), confirming the spondylolisthesis reduction and demonstrating results of the laminectomy and the resolution of the neural compression.

\section{RESULTS}

Table 1 provides a description of the scale proposed by Prolo, et al.,[22] for rating functional and economic status. In Table 2 a summary of demographic, clinical, economic, functional, and radiological pre- and postoperative data is provided for each patient.

\begin{tabular}{|c|c|}
\hline & $\begin{array}{c}\text { TABLE } 2 \\
\text { PROLO ECONOMIC AND FUNCTIONAL RATING SCALE }\end{array}$ \\
\hline Grade & Description \\
\hline econor & ic (activity) status \\
\hline 1 & complete in walid (worse) \\
\hline 2 & no gainful occupation (including housework or retirement activities) \\
\hline 3 & working bctive but not at premortid le wel \\
\hline 4 & working active at previous le vel in'limitation \\
\hline 5 & working bactive at previous le vel wo restriction \\
\hline functio & al (pain) status \\
\hline 1 & total incapacity (worse) \\
\hline 2 & moderate-to-severe daily pain (no change) \\
\hline 3 & low level of daily pain (im proved) \\
\hline $\begin{array}{l}4 \\
5\end{array}$ & occasional or e pisodic pain \\
\hline & no pain \\
\hline
\end{tabular}

Fourteen SOCON-SRI systems and 60 transpedicular screws were implanted. Fusion was performed at one vertebral level in 12 patients and at two levels in two patients: L5--S1 in eight cases, L4--5 in and six, L3--4 in two cases. The average follow-up period was 14 months (range $8--18$ months). Fusion was achieved in all cases, as documented at follow-up examinations, with no evidence of motion on flexion--extension radiographs. No major surgery-related complications occurred in our patients, in terms of wound infection, additional neurological dysfunction, dural tears, or vascular injuries due to screw 
placement. No patient died, required reoperation, or hardware removal after fusion.

The average measured preoperative slippage was 49\% (range 30--65\%). Postoperatively, the average slippage was 19\% (range $15--25 \%)$.

On sensory examination significant improvement was demonstrated in four (50\%) of eight patients. Motor disturbances improved in four (80\%) of five cases. Reflex responses were not shown to change appreciably after surgery in our patients, presumably because of both the long-lasting clinical symptoms and the limited duration of the follow-up period. Significant amelioration of function was seen in the three patients with preoperative urinary incontinence.

The average preoperative economic grade was 2.4 (range 1--4). Postoperatively, the economic grade was 3.6 (range 2--5). Eight patients (57\%) returned to their premorbid level of activities of daily living and were considered to have made good outcomes (Grades 4--5). Three patients (21\%) although improved, had a reduced level of activity (economic Grade 3 ). Three cases (21\%) did not returned to their premorbid level of activity (Grades 1--2). The average change in grade, designated as delta E, in this series was 1.2 .

The mean preoperative functional grade was 2.2 (range 1--4). Postoperatively, the functional grade was 3.6 (range 2--5). Eight patients (57\%) reported a significant functional amelioration, with absent or occasional leg and back pain, and were considered to have made good outcome (grade 4--5). Fair functional outcome was observed in six patients (43\%) who partially improved, but in whom residual leg and low-back pain were still present (Grade 3); these patients did not return to previous work and life style. The average change in function in this series, designated as delta F, was 1.2.

Cigarette smoking did not affect the results obtained in our patients.

\section{DISCUSSION}

A retrospective review of 14 adult patients with spondylolisthesis treated with autologous facet joint fusion and implantation of the SOCON-SRI system was performed. A high rate of successful fusion was obtained using this technique, and it was correlated with clinical, economic, and functional amelioration. The efficacy of the surgical procedure, together with the instrumentation implantation, was evaluated by comparing pre- and postoperative clinical data and neuroradiological findings. No instrumentation-related complication occurred. Although we recognize the complexity of the problem, the large number of variables involved in the pathophysiological mechanisms of spondylolisthesis, the different results reported in the literature, the fact that our results are based on a small series of patients, which somehow limits its applicability and suggests caution in drawing definite conclusions, it can be concluded that spondylolisthesis can be successfully treated with posterior fusion and implantation of the SOCON-SRI system.

The curvature of the normal spine provides for balance of the body's weight by maintaining the center of gravity in the sagittal plane over the vertical axis. $[2,26]$ This relationship can be distorted by alteration of the normal spinal curvature or by other changes, resulting in shifting of the center of gravity. The resulting vector generated by posterior elements and axial load forces eliminates shearing forces. In spondylolisthesis there is a failure of the compensatory mechanisms to maintain an adequate posteriorly directed force vector in opposition to the aforementioned shear forces.[8,16] Although spondylolisthesis was recognized as a distinct clinical entity more than two centuries ago[2,16] and it affects more than $5 \%$ of the general population, $[8,11]$ it continues to generate considerable controversy regarding its 
pathophysiology and management. Medical nonoperative management is indicated as the initial treatment in spondylolisthesis.[2,17,25] In patients with neurological deficits or pain that significantly inhibits lifestyle and in whom nonsurgical management fails to restore comfort and function, consideration of surgical options is warranted. Selection of patients for surgery represents an important aspect of the treatment of spondylolisthesis. In adults, surgical indications include younger age, degree of slippage greater than $25 \%$, movement exceeding $3 \mathrm{~mm}$ as demonstrated on flexion--extension $\mathrm{x}$-ray studies, work-related problems, and previous surgery.[9,15,18]

A number of options exist for spinal fusion in patients with spondylolisthesis. Fusion can be performed from an anterior or posterior approach.[1,2,12] With the anterior approach, interbody grafting represents the most commonly used type of fusion, but this approach can prove difficult if the L-5 vertebral body is displaced over the sacrum, because the resulting position of the interspace is then directed inferiorly, away from the surgeon's view.[14] The posterior approach is most commonly used because it provides the necessary exposure for both neural element decompression and fusion. The posterior approach can be performed for posterior (facet joint), posterolateral (intertransverse), and posterior interbody fusion or as a combination of these, with or without placement of graft material. However, the posterior approach alone has been shown to result in high grades of pseudarthosis formation, as well as an added degree of spinal instability in the early postoperative period.[3,11,12,25]

The use of instrumentation in spinal fusion operations has received increasing attention in the surgical literature, appearing as the treatment of choice because of its association higher fusion rate as well as better clinical results.[2,9] The development of internal fixation systems dates back to the use of the Harrington distraction system in 1951, initially used for the treatment of scoliosis and later for stabilization of fractures, as well as for the treatment of spondylolisthesis.[3--6,24] Numerous devices such as wires, cables, hooks, plates, and screw/rod have been developed for spinal fixation. In lumbar and lumbosacral fixation, actually, screw and rod systems appear to be more effective than hook and rod systems or devices involving sublaminar wires, primarily because of difficulties in attaching to the sacrum and a high complication rate.[2,13] In addition, plate stabilization usually needs the inclusion of healthy adjacent motion segments, and some devices are not yet approved by the United States Food and Drug Administration for general use in the lumbar spine and, most important, may represent a possible source of medicolegal concern for spinal surgeons.

The development of modern titanium devices allows for a complete postoperative neuroradiological assessment for both fusion rates and decompressive procedures. Titanium possesses excellent resistance to corrosion, surpassing that of stainless steel in the human body. Additional bioengineered design features also are used because of titanium's greater notch sensitivity and crack propagation tendencies, as compared with stainless steel.

There is still need for an optimum instrumentation system that can restore the biomechanics of the fused vertebral segments, as well as relieve pain, and enhance resolution of neurological deficit.

The SOCON-SRI system is a dynamic device that allows the manipulation of each instrumented vertebra.[26] In addition, distraction and reduction procedures can be performed to restore the normal neural space. This system consists of transpedicular bone screws, straight and prebent rods, and specially designed clamps that can be tightened by one locking screw. The reduction instrumentation system can be connected directly to the ends of the bone screws, allowing for a wide variety of corrective procedures. It has to be emphasized that, prior to placement of the SOCON-SRI implant, it is mandatory 
to perform microsurgical nerve root decompression to avoid iatrogenic lesions from the repositioning of the anteriorly displaced vertebra and to reduce spinal compression. The two roots in the recesses of the affected segment, as well as the entire cauda equina, may be squeezed between the withdrawn vertebral body and degenerated hypertrophic facet joint of the lower vertebra.[21] From a biomechanical point of view, the possibility of restoring the normal relationship between the two vertebral bodies seems to be important to reduce the stress caused by the so-called "shearing forces on the spinal construct."[2]

\section{CONCLUSIONS}

Improved intraoperative techniques and postoperative care have reduced operative complications in spondylolisthesis surgery and have permitted spondylolisthesis to be treated in more cases than was previously possible. Our findings, taken together with those of others, regarding both the feasibility and benefit of dedicated dynamic titanium devices for spondylolisthesis, support a recommendation for surgery, when indicated. Posterior facet joint fusion combined with placement of the SOCON-SRI implant is a safe and efficacy surgical option in the treatment of spondylolisthesis, as it prevents progression of neurological deficits, enhances recovery of existing deficits, relieves pain, stabilizes abnormal motion, prevents additional slippage progression, and significantly ameliorates both economic and functional outcomes.

\section{References}

1. Abdu WA, Wilber RG, Emery SE: Pedicular transvertebral screw fixation of the lumbosacral spine in spondylolisthesis. A new technique for stabilization. Spine 19:710-715, 1994

2. Baldwin NG: Lumbar spondylolysis and spondylolisthesis, in Menezes AH, Sonntag VHK (eds): Principles of Spinal Surgery. New York: McGraw-Hill, 1996, Vol 1, pp 681-703

3. Boos N, Marchesi D, Zuber K, et al: Treatment of severe spondylolisthesis by reduction and pedicular fixation. A 4-6-year follow-up study. Spine 18:1655-1661, 1993

4. Cotrel Y, Dubousset J, Guillaumat M: New universal instrumentation in spinal surgery. Clin Orthop 227:10-23, 1988

5. Dick W: The "fixateur interne" as a versatile implant for spine surgery. Spine 12:882-900, 1987

6. Dick W, Kluger P, Magerl F, et al: A new device for internal fixation of thoracolumbar and lumbar spine fractures: the "fixateur interne." Paraplegia 23:225-232, 1985

7. Dickman CA, Fessler RG, MacMillan M, et al: Transpedicular screw-rod fixation of the lumbar spine: operative technique and outcome in 104 cases. J Neurosurg 77:860-870, 1992

8. Fredrickson BE, Baker D, McHolick WJ: The natural history of spondylolisis and spondylolisthesis. J Bone Joint Surg (Am) 66:699-707, 1984

9. Frymoyer JW: Back pain and sciatica. N Engl J Med 318:291-300, 1988

10. Frymoyer JW, Selby DK: Segmental instability. Rationale for treatment. Spine 10:280-286, 1985

11. Hu SS, Bradford DS, Transfeldt EE, et al: Reduction of high-grade spondylolisthesis using Edwards instrumentation. Spine 21:367-371, 1996 
12. Karahalios DG, Apostolides PJ, Sonntag VKH: Technique of pedicle screw fixation of the lumbosacral spine. Operative Tech Neurosurg 1:134-141, 1998

13. Kostuik JP, Errico TJ, Gleason TF: Luque instrumentation in degenerative conditions of the lumbar spine. Spine 15:318-321, 1990

14. Laurent LE, Österman K: Operative treatment of spondylolisthesis in young patients. Clin Orthop 117:85-91, 1976

15. Lee TC: Reduction and stabilization without laminectomy for unstable degenerative spondylolisthesis: a preliminary report. Neurosurgery 35:1072-1076, 1994

16. Meyerding HW: Spondylolisthesis. Surg Gynecol Obstet 54:371-377, 1932

17. Möller J, Wittemberg RH, Nolte LP, et al: Results of lumbosacral distraction spondylodesis for treatment of spondylolisthesis, failed back syndrome, and lumbar instability. Eur Spine J 1:117-124, 1992

18. Nasca RJ: Rationale for spinal fusion in lumbar spinal stenosis. Spine 14:451-454, 1989

19. Nolte LP, Steffen R, Krämer J, et al: Der Fixateur interne: eine vergleichende biomechanischeStudie verschiedener Systeme. Akta Traumatol 23:20-26, 1993

20. Ohmori K, Suzuki K, Yoshihiro I: Translamino-pedicular screw fixation with bone grafting for symptomatic isthmic lumbar spondylolysis. Neurosurgery 30:379-384, 1992

21. Plotz GM, Benini A: Surgical treatment of degenerative spondylolisthesis in the lumbar spine: no reposition without prior decompression. Acta Neurochir 137:188-191, 1995

22. Prolo DJ, Oklund SA, Butcher M: Toward uniformity in evaluating results of lumbar spine operation. A paradigm applied to posterior lumbar interbody fusions. Spine 11:601-606, 1986

23. Rohlmann A, Calisse J, Bergmann G, et al: Clamping stiffness and its influence on load distribution between paired internal spinal fixation devices. J Spinal Disord 9:234-240, 1996

24. Roy-Camille R, Saillant G, Mazel C: Internal fixation of the lumbar spine with pedicle screw plating. Clin Orthop 203:7-17, 1986

25. Schnee CL, Freese A, Ansell LV: Outcome analysis for adults with spondylolisthesis treated with posterolateral fusion and transpedicular screw fixation. J Neurosurg 86:56-63, 1997

26. Wittemberg H, Steffen R, Willburger RE, et al: Biomechanics and clinical results of the SOCON Spinal System, in Szpalski M (ed): Instrumented Fusion of the Degenerative Lumbar Spine: State of the Art, Question, and Controversies. Philadelphia: Lippincott-Raven Publishers, 1996, pp 77-90

27. Wood GW II, Boyd RJ, Carothers TA, et al: The effect of pedicle screw/plate fixation on lumbar/lumbosacral autogenous bone graft fusions in patients with degenerative disc disease. Spine 20:819-830, 1995

Manuscript received October 20, 1999. 
Accepted in final form November 11, 1999.

Address reprint requests to: Giovanni La Rosa, M.D., Neurosurgical Clinic, Policlinico Universitario, Via Consolare Valeria, 1, 98122 Messina, Italy. email: germano@unime.it. 